\title{
Composición de la comunidad procariota involucrada en la producción de nitrógeno en sedimentos de la bahía Mejillones
}

Prokaryotic community composition involved production of nitrogen in sediments of Mejillones Bay

\author{
Rubén Moraga ${ }^{1,2}$, Alexander Galan ${ }^{3}$, Ramón Rossello-Mora ${ }^{4}$, \\ Rubén Araya ${ }^{5,6}$ y Jorge Valdés ${ }^{7,8}$
}

${ }^{1}$ Laboratorio de Microbiología, Facultad de Recursos Naturales y Renovables, Universidad Arturo Prat, Casilla 121, Iquique, Chile. rmoraga@unap.cl

${ }^{2}$ Programa de Doctorado Cs. Biológicas, Facultad de Ciencias de la Salud, Universidad de Antofagasta, Casilla 170, Antofagasta, Chile ${ }^{3}$ Departamento de Oceanografía, Facultad de Ciencias Naturales y Oceanográficas, Universidad de Concepción, Casilla 160-C, Concepción, Chile

${ }^{4}$ Laboratorio de Microbiología, Instituto Mediterráneo de Estudios Avanzados (CSIC-UIB), E-07071, Palma de Mallorca, España 5Instituto de Ciencias Naturales 'Alexander Von Humboldt', Facultad de Ciencias del Mar y de Recursos Biológicos, Universidad de Antofagasta, Casilla 170, Antofagasta, Chile

${ }^{6}$ Instituto Antofagasta Recursos Naturales Renovables, Facultad de Ciencias del Mar y de Recursos Biológicos, Universidad de Antofagasta, Casilla 170, Antofagasta, Chile

${ }^{7}$ Laboratorio de Sedimentología y Paleoambientes (LASPAL), Instituto de Ciencias Naturales 'Alexander Von Humboldt', Facultad de Ciencias del Mar y de Recursos Biológicos, Universidad de Antofagasta, Casilla 170, Antofagasta, Chile

${ }^{8}$ Laboratorio Mixto Internacional PALEOTRACES, Institut de Recherche pour le Développment, Universidade Federal Fluminense, Universidad de Antofagasta, Casilla 170, Antofagasta, Chile

Abstract.- Conventional denitrification and anaerobic ammonium oxidation (anammox) contributes to nitrogen loss in oxygen-deficient systems, thereby influencing many aspects of ecosystem function and global biogeochemistry. Mejillones Bay, northern Chile, presents ideal conditions to study nitrogen removal processes, because it is inserted in a coastal upwelling system, its sediments have anoxia and hypoxia conditions and under the influence of the Oxygen Minimum Zone (OMZ), unknown processes that occur there and what are the microbial communities responsible for their removal. Microbial communities associated with coastal sediments of Mejillones Bay were studied by denaturing gel electrophoresis (DGGE) and fluorescence in situ hybridization (FISH), by incubation experiments with ${ }^{15} \mathrm{~N}$ isotope tracers were studied nitrogen loss processes operating in these sediments. DGGE analysis showed high bacterial diversity, certain redundant phylotypes and differences in community structure given by the depth; this reflects the microbial community adaptations to environmental conditions. A large fraction (up to 70\%) of DAPI-stained cells hybridized with the bacterial probes. Nearly $52-90 \%$ of the cell could be further identified to know phyla. Members of the Cytophaga-Flavobacterium cluster were most abundant in the sediments (13-26\%), followed by Proteobacteria. Isotopic tracer experiments for the sediments studied indicated that nitrogen loss processes that predominated were performed by denitrifying communities (43.31-111.20 $\mu \mathrm{M}$ $\mathrm{d}^{-1}$ ) was not possible to detect anammox in the area and not anammox bacteria were detected.

Key words: Production of $\mathrm{N}_{2}$, denitrification, anammox, marine sediments

Resumen.- La desnitrificación convencional y la oxidación anaeróbica del amonio (anammox), son procesos que contribuyen a la pérdida de $\mathrm{N}$ en los sistemas deficientes de oxígeno, determinando en muchos aspectos el funcionamiento de los ecosistemas y su biogeoquímica global. Bahía Mejillones, norte de Chile, presenta condiciones ideales para estudiar los procesos de remoción del nitrógeno, debido a que está inserta en un sistema de surgencia costera y sus sedimentos presentan condiciones de anoxia e hipoxia generadas por la influencia de la Zona Mínima de Oxigeno (ZMO), desconociéndose los procesos que regulan la pérdida de nitrógeno y cuáles son las comunidades microbianas responsables de su remoción. Las comunidades microbianas asociadas a los sedimentos costeros de bahía Mejillones se estudiaron por electroforesis en geles de gradiente denaturante (DGGE) y por hibridación in situ fluorescente (FISH), mientras que los procesos de remoción de $\mathrm{N}$ se estudiaron mediante experimentos de incubación con trazadores isotópicos ${ }^{15} \mathrm{~N}$. EI análisis por DGGE indicó una alta diversidad bacteriana, ciertos filotipos redundantes y la existencia de diferencias en la estructura comunitaria dada por la profundidad y la estacionalidad, lo que refleja adaptaciones de la comunidad microbiana frente a las condiciones ambientales imperantes. Los análisis realizados mediante FISH revelaron que sobre el $70 \%$ de las bacterias teñidas con DAPI hibridaron con las sondas específicas, cerca del 52 al $90 \%$ de estas fueron asignadas a phyla conocidos. Miembros del cluster Cytophaga-Flavobacterium fueron los más abundantes (13-26\%), seguido por Proteobacteria (9-21\%). Los experimentos con trazadores isotópicos indicaron para los sedimentos estudiados que los procesos de remoción de nitrógeno que predominaron fueron realizados por comunidades desnitrificantes (43,31-111,20 $\mu \mathrm{M} \mathrm{d}^{-1}$ ) no detectándose anammox ni las bacterias responsables de dicho proceso.

Palabras clave: Producción de $\mathrm{N}_{2}$, desnitrificación, anammox, sedimentos marinos 


\section{INTRODUCCIÓN}

Los sedimentos marinos que se encuentran a lo largo de los márgenes continentales juegan un rol importante en el reciclamiento global de los nutrientes (Rochelle et al. 1994). Particularmente el incremento del ingreso de carbón y nutrientes en estos sedimentos, resulta en un rápido reciclamiento por parte de las comunidades microbianas (Tiquia et al. 2006). Se ha sugerido que en la actualidad existe un desbalance en el ciclo del nitrógeno, debido a su pérdida en los océanos, principalmente por la actividad de desnitrificación (Codispoti 1995, Middleburg et al. 1996).

La desnitrificación es un proceso de respiración bacteriana anaeróbico, el cual usa al nitrato como aceptor de electrones, convirtiendo el nitrógeno iónico a gaseoso, forma por la cual éste se pierde desde el océano a la atmósfera.

En décadas recientes, el descubrimiento de nuevas formas por las cuales el nitrógeno $(\mathrm{N})$ es removido del sistema, ha cambiado la visión del ciclo. La pérdida del $\mathrm{N}$ a partir de la oxidación anaeróbica del amonio (Mulder et al. 1995), proceso llamado anammox, ha sido reconocido como un importante mecanismo que cambia los balances y dinámica del $\mathrm{N}$ en los sistemas marinos (Dalsggard \& Thamdrup 2002). Bajo condiciones anóxicas el amonio es oxidado por bacterias autotróficas anammox a gas dinitrógeno $\left(\mathrm{N}_{2}\right)$, consumiendo el nitrito como aceptor de electrones.

En los océanos, el $30-50 \%$ de la pérdida total de $\mathrm{N}$ ocurre en las zonas de mínima de oxigeno (ZMO). La ZMO es una característica particular de los sistemas de corrientes de los bordes orientales continentales, como es el caso de los afloramientos costeros de Chile-Perú, California, Benguela y el mar de Arabia (Barber \& Smith 1981).

Recientemente, el estudio con trazadores isotópicos del ${ }^{15} \mathrm{~N}$ mostró que en la ZMO del norte de Chile y sur del Perú, la remoción de nitrógeno del sistema fue por acción de los procesos de anammox, no detectándose procesos de desnitrificación (Thamdrup et al. 2006). Se ha estimado que el proceso anammox puede contribuir sobre el 50\% de la remoción del $\mathrm{N}$ de los océanos en forma global (Rysgaard et al. 2004, Arrigo 2005, Capone \& Hutchins 2013). Tema aún bajo discusión, Dalsgaard et al. (2012) señalan que la distribución irregular de la desnitrificación en la zona norte del país contribuye a explicar los aparentes desequilibrios entre las fuentes de amonio y los sumideros sugeridos por estudios anteriores basados en ${ }^{15} \mathrm{~N}$ en la ZMO (Castro-González \& Farías 2004, Farías et al. 2009).

Estudios en el Pacifico Sur Tropical Oriental señalan que la costa norte de Chile está bajo la influencia de una de las zonas donde la ZMO es más intensa (Morales et al. 1999). En esta zona la ocurrencia de un centro permanente de surgencia costera y la existencia de una plataforma continental estrecha propician que aguas deficientes en oxígeno puedan llegar a la capa fótica, con una gran variabilidad en su distribución en relación a la profundidad (Ulloa et al. 2001, Galán et al. 2009).

La bahía de Mejillones $\left(23^{\circ} \mathrm{S}\right)$, localizada a $60 \mathrm{~km}$ al norte de Antofagasta, es una área cerrada de afloramiento costero, la cual es conocida por ser un centro de deposición sedimentaria de materia orgánica (Valdés 2004). Al interior de la bahía se encuentran 3 cuerpos de aguas: agua subtropical superficial (ASST), agua superficial subantártica (ASSA) y agua ecuatorial subsuperficial (AESS), las cuales varían en su grado de mezcla durante el año (Valdés et al. 2006). Las condiciones fisicoquímicas de la bahía como temperatura, salinidad y oxígeno disuelto, tienen una variación estacional, mostrando un período frío (otoño-invierno) y uno cálido (primavera-verano) (Rodríguez \& Escribano 1996, Valdés et al. 2003). Por otro lado, la bahía de Mejillones se encuentra bajo la influencia de la ZMO, la cual se extiende desde el sur del Perú hasta la región central de Chile, y se localiza entre los 50 y $500 \mathrm{~m}$ de profundidad frente a la costa de Mejillones (Strub et al. 1998). La profundidad máxima de la bahía es $110 \mathrm{~m}$, razón por la cual gran parte del fondo se encuentra bajo la influencia de la ZMO, así la bahía de Mejillones representa un área de estudio ideal para investigar el ciclo del nitrógeno en relación a los procesos microbiológicos que ocurren en los sedimentos y que se relacionan con su remoción. Son escasos los estudios en la zona que dan cuenta de la diversidad microbiana presentes en la bahía como en la ZMO que den cuenta de estos procesos (Stevens \& Ulloa 2008, Farías et al. 2009).

De acuerdo a lo señalado se ha determinado mediante la técnica de apareamiento isotópico, la estrategia de remoción del nitrógeno que utilizarían las comunidades microbianas en bahía Mejillones, describiendo la composición de estas comunidades asociadas a los sedimento mediante hibridación in situ fluorescente (FISH) y electroforesis en gel en gradiente denaturante (DGGE). 


\section{Materiales y MÉTODOS}

\section{Sitio de ESTUdio Y MUESTREO}

Los sedimentos fueron recolectados con un box core de un área de $225 \mathrm{~cm}^{2}$, desde 4 transectos perpendiculares a la línea de costa, localizadas al interior de bahía Mejillones $\left(23^{\circ} \mathrm{S}\right)$, individualizadas como T1: Punta Chacaya, T2: industrial, T3: Capitanía y T4: Punta Rieles (Fig. 1). Desde cada transecto las muestras fueron recolectadas en triplicado a partir de sucesivos dragados a 10, 25, 50 y 75 $\mathrm{m}$ de profundidad. Las muestras se depositaron en viales plásticos y fueron almacenados a $4^{\circ} \mathrm{C}$ para su transporte al laboratorio. Adicionalmente, se recolectaron submuestras con un saca testigo de gravedad $(5,2 \mathrm{~cm}$ de diámetro), los cuales fueron usados para los experimentos con trazadores isotópicos.

\section{Análisis granulométrico y determinación de MATERIA ORGÁNICA}

El análisis granulométrico se realizó mediante el uso de un agitador de tamices, el cual permitió separar las diferentes fracciones de sedimento presentes en las muestras recolectadas; éstas fueron descritas de acuerdo a la escala de tamaño de partículas de Wentworth (Wentworth 1922). La determinación de materia orgánica
(MO) se realizó de acuerdo a la metodología descrita por Nelson \& Sommers (1982), mediante calcinación. Las muestras de sedimento fueron secadas a $90^{\circ} \mathrm{C}$ por $12 \mathrm{~h}$, para posteriormente ser pesadas en una balanza analítica, y calcinadas a $500^{\circ} \mathrm{C}$ por $6 \mathrm{~h}$. La diferencia de peso entre la muestra seca y la muestra calcinada corresponde a la materia orgánica, la que fue expresada como porcentaje del peso seco libre de cenizas.

\section{RECUENTO POR DAPI E HIBRIDACIÓN IN SITU FLUORESCENTE (FISH)}

Las muestras fueron fijadas de acuerdo al procedimiento descrito por Llobet-Brossa et al. (1998), utilizando el protocolo optimizado para la identificación de arquea y bacteria en sedimentos marinos (Ishii et al. 2004). Hibridación, tinción con DAPI y microscopia se realizaron de acuerdo a lo descrito previamente por Snaidr et al. (1997). Por cada muestra en triplicado se contaron a lo menos 700 células. Estas células fueron visualizadas en un microscopio Leitz® acoplado a una cámara Sony®, capturando 14 imágenes aleatorias para su posterior análisis, mediante la utilización del software Image $\mathrm{J}^{1}$. Las células teñidas con DAPI y sondas marcadas con el fluorocromo $\mathrm{Cy} 3$ fueron visualizadas usando 2 set de filtros (330/420 nm y $480 / 590 \mathrm{~nm}$, respectivamente). Las sondas usadas se indican en la Tabla 1.

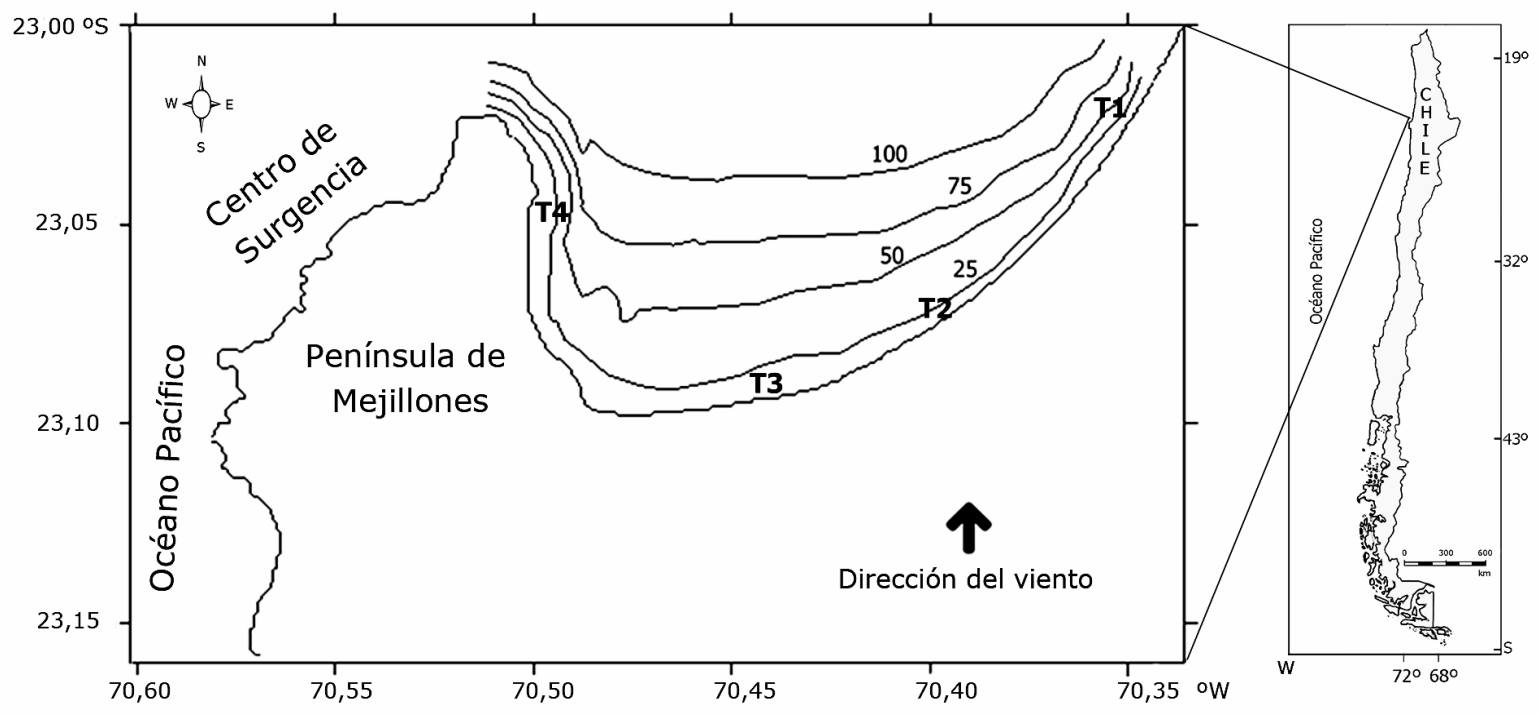

Figura 1. Localización de los transectos de muestreos en bahía Mejillones, Chile / Localization of sampling stations in Mejillones Bay, Chile

${ }^{1}$ U.S. National Institutes of Health <http://rsb.info.nih.gov/nih-image/> 
Tabla 1. Sondas de oligonucleótidos usados en este estudio / Oligonucleotide probes used in this study

\begin{tabular}{|c|c|c|c|c|}
\hline Sonda & Especificidad & Secuencia $\left(5^{\prime}-3\right)$ & $\begin{array}{l}\mathrm{FA}^{\mathrm{a}} \\
(\%)\end{array}$ & Referencia \\
\hline EUB mix & Bacteria & Mezcla de las tres sondas & 55 & \\
\hline EUB338 & Mayoría Bacteria & GCTGCCTCCCGTAGGAGT & & Amann et al. (1990) \\
\hline EUB338II & Plantomycetes & GCAGCCACCCGTAGGTGT & & Daims et al. (1999) \\
\hline EUB338III & Verrucomicrobium spp. & GCTGCCACCCGTAGGTGT & & Daims et al. (2002) \\
\hline NON338 & Antisentido EUB338 & ACTCCTACGGGAGGCAGC & 55 & Wallner et al. (1993) \\
\hline ALF968 & Alphaproteobacteria & GGTAAGGTTCTGCGCGTT & 20 & Reed et al. (2002) \\
\hline BET42a & Betaproteobacteria & GCCTTCCCACTTCGTTT & 35 & Manz et al. (1992) \\
\hline $\begin{array}{l}\text { GAM42a } \\
\text { DELTA mix }\end{array}$ & $\begin{array}{l}\text { Gammaproteobacteria } \\
\text { Deltaproteobacteria }\end{array}$ & GCCTTCCCACATCGTTT & 35 & Manz et al. (1992) \\
\hline DELTA495A & $\begin{array}{l}\text { Mayoria } \\
\text { Deltaprotobacteria y } \\
\text { Gemmatimonadtes }\end{array}$ & AGTTAGCCGGTGCTTCCT & 35 & Lücker et al. (2007) \\
\hline DELTA495B & $\begin{array}{l}\text { Algunas } \\
\text { Deltaproteobacteria }\end{array}$ & AGTTAGCCGCTTCCT & 35 & Lücker et al. (2007) \\
\hline DELTA495C & $\begin{array}{l}\text { Algunas } \\
\text { Deltaproteobacteria }\end{array}$ & AATTAGCCGGTGCTTCCT & 35 & Lücker et al. (2007) \\
\hline SRB385 & Deltaproteobacteria & CGGCGTCGCTGCGTCAGG & 35 & Rabus et al. (1998) \\
\hline CF319A & $\begin{array}{l}\text { Cluster Cytophaga- } \\
\text { Flavobacterium }\end{array}$ & TGGTCCGTGTCTCAGTAC & 35 & Manz et al. (1996) \\
\hline BS 820 & Scalindua sorkinii & TAATTCССТCTACTTAGTGCCC & 25 & Kuypers et al. (2003) \\
\hline BS820C & Scalindua brodae & TAATCCCCTCTACTTAGTGCCC & 25 & Hamersley et al. (2007) \\
\hline ARCH915 & Archaea & GTGCTCCCGCAATTCCT & 35 & Stahl \& Amann (1991) \\
\hline
\end{tabular}

${ }^{\text {a } C o n c e n t r a c i o ́ n ~ d e ~ F o r m a m i d a ~ u s a d a ~ e n ~ e l ~ b u f f e r ~ d e ~ F I S H ~}$

\section{EXTRACCión dE ADN y PCR}

El ADN genómico asociado a las comunidades bacterianas en sedimentos fue extraído del sedimento mediante la utilización del kit Power Soil (Mo Bio) de acuerdo a las instrucciones del proveedor, a partir de $0,3 \mathrm{~g}$ de sedimentos. Las amplificaciones de PCR se realizaron utilizando los partidores UBf933-GC-Clamp y EUBr1397, los cuales son específicos para secuencias conservadas del gen 16 S de bacteria (Iwamoto et al. 2000). Para prevenir la completa disociación de los fragmentos de ADN para el análisis mediante DGGE, se incorporó una cola de 40 pb, rica en GC al extremo 5' del primer EUBf933 (Myers et al. 1985). Las amplificaciones se realizaron de acuerdo a lo descrito por Araya et al. (2008), que consistió en una 'partida en caliente' a $95^{\circ} \mathrm{C}$ por 9 min, seguido de un 'decremento' de la temperatura de alineamiento, la cual se inició a $65^{\circ} \mathrm{C}$ y luego se redujo en $0,5^{\circ} \mathrm{C}$ por cada ciclo hasta llegar a $55^{\circ} \mathrm{C}$, seguida de una extensión de los partidores a $72^{\circ} \mathrm{C}$ por $3 \mathrm{~min}$. Posteriormente, se realizaron 15 ciclos adicionales a $55^{\circ} \mathrm{C}$ por 1 min (alineamiento de los partidores), con una desnaturación a $94^{\circ} \mathrm{C}$, por $1 \mathrm{~min}$ y extensión de los partidores a $72^{\circ} \mathrm{C}$, por $3 \mathrm{~min}$, con una extensión final a $72^{\circ} \mathrm{C}$ por $7 \mathrm{~min}$.

\section{Análisis mediante electroforesis en Geles en GRADIENTE DENATURANTE}

Aproximadamente, $300 \mathrm{ng}$ de los productos de PCR se cargaron en un gel de poliacrilamida $(6,5 \% \mathrm{w} / \mathrm{v})$, con un gradiente denaturante de 45 a $65 \%$ (urea-formamida). La electroforesis se corrió por $12 \mathrm{~h}$ a $100 \mathrm{~V}$ en buffer TAE $1 \mathrm{x}$. Los geles fueron teñidos con SYBR gold (Molecular Probes), durante $20 \mathrm{~min}$, de acuerdo a las instrucciones 
del proveedor. Finalmente, los geles de DGGE fueron visualizados mediante un transiluminador (Vilver Lourmat TFX20M) equipado con una cámara digital (QImaging). Las imágenes fueron analizadas mediante el programa Gelpro analyzer (v 4.0 Media Cybernetics, Inc.) para generar un perfil densitométrico de las bandas, las cuales fueron exportadas a una planilla Excel. La detección de las bandas se registró cuando la intensidad de ésta excedió al 1\% del pico total de la gráfica. El estudio de las bandas representativas de las comunidades bacterianas se llevó a cabo mediante un análisis por escalamiento multidimensional no métrico (MDS), mediante el uso de una matriz de similitud de Bray \& Curtis (1975). Con los resultados de cada muestra se calcularon los índices ecológicos: número de especie, abundancia y diversidad, el número de bandas se usó para indicar el número de especies (S); la intensidad relativa de cada banda en relación a la intensidad del gel se utilizó para estimar la abundancia de especies. Los índices de diversidad de Shannon (Shannon \& Weaver 1963) y de equitabilidad (Pielou 1966) fueron calculados con los mismos parámetros indicados. Toda la información se analizó con el programa Primer 6.0 (Plymouth Marine Laboratory), la significancia estadística de los índices se llevó a cabo con el programa Ecological Community Analysis 2.01 (Pisces Conservation Ltd.).

\section{${ }^{15} \mathrm{~N}$-MARCAJE, INCUBACIÓN Y ANÁLISIS}

Las incubaciones con ${ }^{15} \mathrm{~N}$ fueron realizadas de acuerdo a Thamdrup et al. (2006), en compuestos de nitrógeno marcados como trazadores: ${ }^{15} \mathrm{NH}_{4}^{+},{ }^{15} \mathrm{NO}_{3},{ }^{15} \mathrm{NO}_{2}^{-}$. Las concentraciones finales de los trazadores fueron $5 \mu \mathrm{M}$ amonio, nitrito $50,1 \mu \mathrm{M}$ y $50,2 \mu \mathrm{M}$ nitrato. Los primeros 2 $\mathrm{cm}$ de sedimento del testigo por triplicado fueron usados para la incubación. Las muestras para incubación fueron procesadas en atmósfera de helio. Los lodos se realizaron en un vaso precipitado, adicionando $\sim 150 \mathrm{~mL}$ de agua de mar filtrada $(0,2 \mu \mathrm{m}$ tamaño de poro) para obtener un volumen de $\sim 200 \mathrm{~mL}$. Posteriormente, los trazadores fueron inoculados en los sedimentos y las muestras distribuidas en viales de vidrio de $\sim 5 \mathrm{~mL}$ (Exetainers, Labco, UK), mediante una jeringa acondicionada con un catéter de pequeño diámetro, e incubadas a temperatura in situ $\left(13^{\circ} \mathrm{C}\right)$ por $36 \mathrm{~h}$. Las muestras se tomaron en triplicado a las $0,3,6,12,18,24,36$ h, retirando $4 \mathrm{ml}$ de la suspensión. En cada muestreo la actividad biológica fue detenida adicionando $100 \mu \mathrm{L}$ de $\mathrm{HgCl}$. La composición de la razón isotópica del $\mathrm{N}_{2}\left({ }^{15} \mathrm{~N}^{14} \mathrm{~N}:{ }^{14} \mathrm{~N}^{14} \mathrm{~N}\right.$ y $\left.{ }^{15} \mathrm{~N}^{15} \mathrm{~N}:{ }^{14} \mathrm{~N}^{14} \mathrm{~N}\right)$ se determinó mediante cromatografía de gases acoplada a espectrofotometría de masas de razón isotópica (GC-irmMS), usando aire como estándar. Las tasas de desnitrificación y anammox en los sedimentos homogenizados fueron calculadas a partir de la producción de ${ }^{29} \mathrm{~N}_{2}$ y ${ }^{30} \mathrm{~N}_{2}$ asumiendo emparejamiento 1:1 del $\mathrm{N}$ desde $\mathrm{NH}_{4}{ }^{+}$y $\mathrm{NO}_{3}{ }^{-}$o $\mathrm{NO}_{2}{ }^{-}$durante anammox y emparejamiento isotópico aleatorio durante la desnitrificación.

\section{Resultados}

\section{Características físicas de los Sedimentos Y RECUENTO DE BACTERIAS TOTALES}

La figura 2 muestra el tamaño y distribución granulométrica de los sedimentos de bahía Mejillones. Estos se caracterizaron por la presencia de sedimentos con un tamaño de grano menor a $100 \mu \mathrm{m}$, lo cual correspondió a limo fino y limo medio. En las regiones cercanas a la costa predominó la presencia de granos de mayor tamaño, correspondiente a arena gruesa (Wentworth 1922). En términos generales, los sedimentos más gruesos se distribuyen en las zonas costeras más someras, mientras que el sedimento más fino predominó en las zonas más profundas.

Los sedimentos presentes en regiones someras $(10 \mathrm{~m})$ registran valores menores al 5\% de MO, con una distribución que se caracterizó por la existencia de bajos valores en los transectos ubicados en las zonas extremas del área de estudio (T1 y T4), incrementándose hacia la zona media de la bahía. Esta situación contrasta con los valores obtenidos para los sedimentos más profundos (75 m), en los que se observó >20\% en contenido de MO en la mayoría de las estaciones (Fig. 3). Por otra parte, no se visualizaron valores altos de materia orgánica asociados a los transectos ubicados en el sector industrial y urbano de la bahía, y tampoco se observaron variaciones estacionales en el contenido de materia orgánica para ninguno de los sitios muestreados.

En la figura 4 se aprecian los recuentos bacterianos obtenidos por tinción DAPI en los sedimentos analizados. Estos recuentos fluctuaron entre 13 a 20 x $10^{8}$ cél. $\mathrm{g}^{-1}$ para el primer periodo de estudio (septiembre 2005), donde se observaron 2 núcleos principales de distribución, uno cercano a la Capitanía de Puerto y en Punta Chacaya, con un ligero incremento en su número. En el segundo período de muestreo (diciembre 2005), se observó un claro decaimiento en la concentración de los microorganismos, con una distribución más homogénea en términos de los 


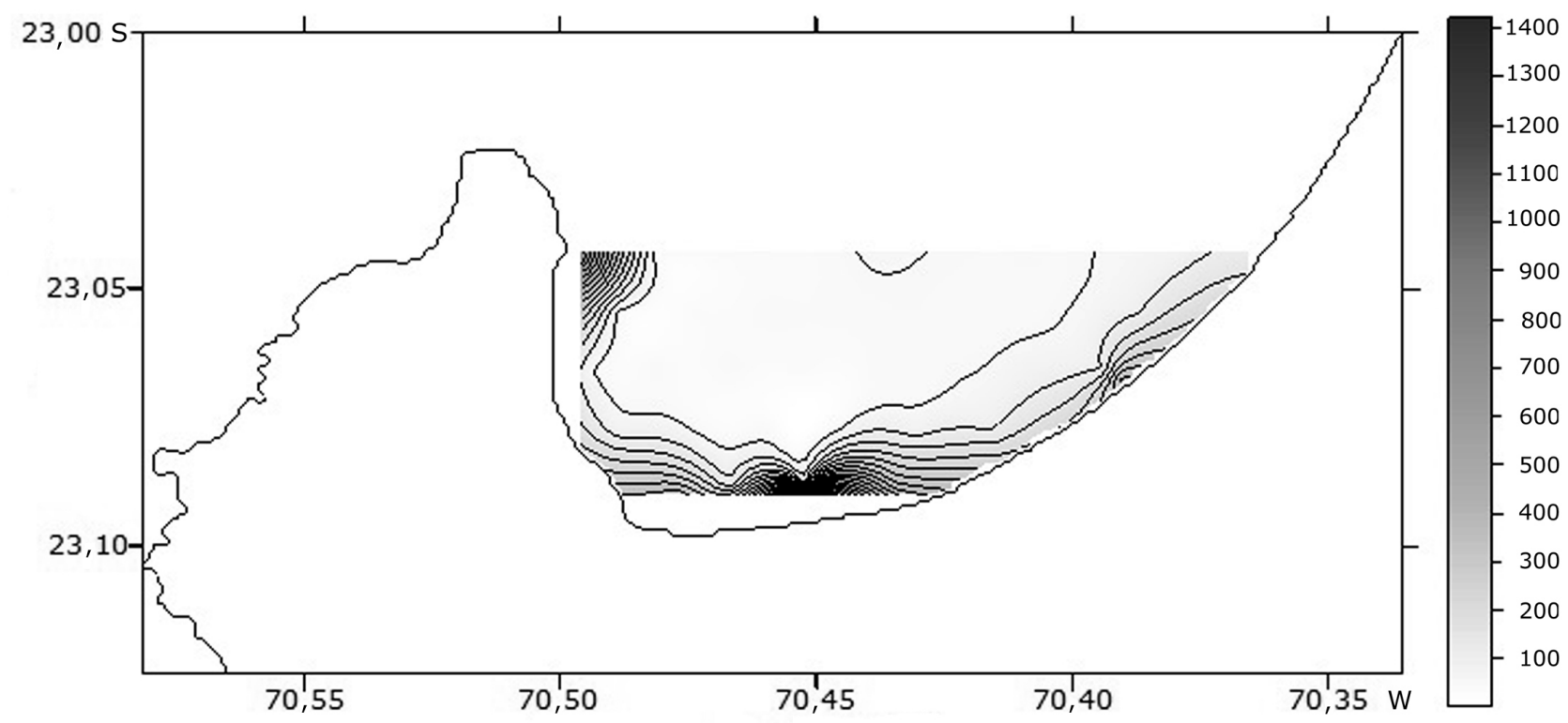

Figura 2. Mapa granulométrico $(\mu \mathrm{m})$ de los sedimentos de bahía Mejillones / Granulometric map $(\mu \mathrm{m})$ of the sedyment of Mejillones Bay

recuentos obtenidos, los cuales estuvieron en el orden de 4 a 9 × $10^{8}$ cél. $\mathrm{g}^{-1}$, debido probablemente a una columna de agua más uniforme y estable, producto de la estratificación termal. En el tercer período de muestreo (mayo 2006), se detectó un incremento en la concentración de microorganismos en los sedimentos analizados $(1,12 \mathrm{x}$ $10^{9} \pm 4,94 \times 10^{8}$ ). Estos mostraron una mayor abundancia en el transecto de la Capitanía de Puerto y sector de Industriales, disminuyendo hacia Punta Chacaya.

Para el periodo en estudio, se establece que los recuentos obtenidos de las comunidades bacterianas asociadas a estos sedimentos, muestran una caída significativa desde un periodo frío (mayo) a uno cálido, como corresponde a los meses de septiembre y diciembre $\left(\mathrm{F}_{(3,83)}=8,21, P<0,013\right)$.

\section{ANÁLISIS POR ELECTROFORESIS EN GEL DE GRADIENTE DENATURANTE (DGGE) E HIBRIDIZACIÓN IN SITU FLUORESCENTE (FISH)}

La huella digital de la comunidad microbiana obtenida por DGGE reflejó las variaciones espacio temporales de ésta en el sedimento superficial. Se identificaron un total de 840 bandas (unidades taxonómicas operacionales o UTO's), el número de éstas varió entre 7 a 32 por muestra, con un promedio de $19 \pm 6$ bandas por estación. Los resultados de la DGGE mostraron que existe una alta diversidad bacteriana en el área de estudio y que la estructura de la comunidad varia espacio temporalmente.

El análisis de MDS permitió visualizar cambios en la estructura comunitaria (Fig. 5); esta ordenación permitió establecer ciertos agrupamientos entre las muestras. En la gráfica del MDS, la distancia entre los puntos reflejan las similitudes del patrón de bandeo del DGGE entre las muestras, y de esta forma las estructuras comunitarias similares están más próximas entre sí. En la figura 5 se observan 3 agrupamientos claramente definidos en base a los OTU's identificadas en los geles; estos agrupamientos confirmaron la interacción dada por la época del estudio y del sitio de donde se obtuvieron las muestras, así como la existencias de bandas únicas y comunes, las que se presentan en los diferentes sitios estudiados. El MDS revela que las comunidades microbianas variaron su estructura durante el período de estudio y dan cuenta de una interacción existente entre los sitios de estudio y los períodos en los cuales se muestreó, se evidencia la separacion de las comundades microbianas de la transecta 4 en las épocas de muestreo en relación al resto de las comunidades. Los resultados del análisis de similitud confirman lo señalado (ANOSIM, $\mathrm{R}=0,59$ ). 


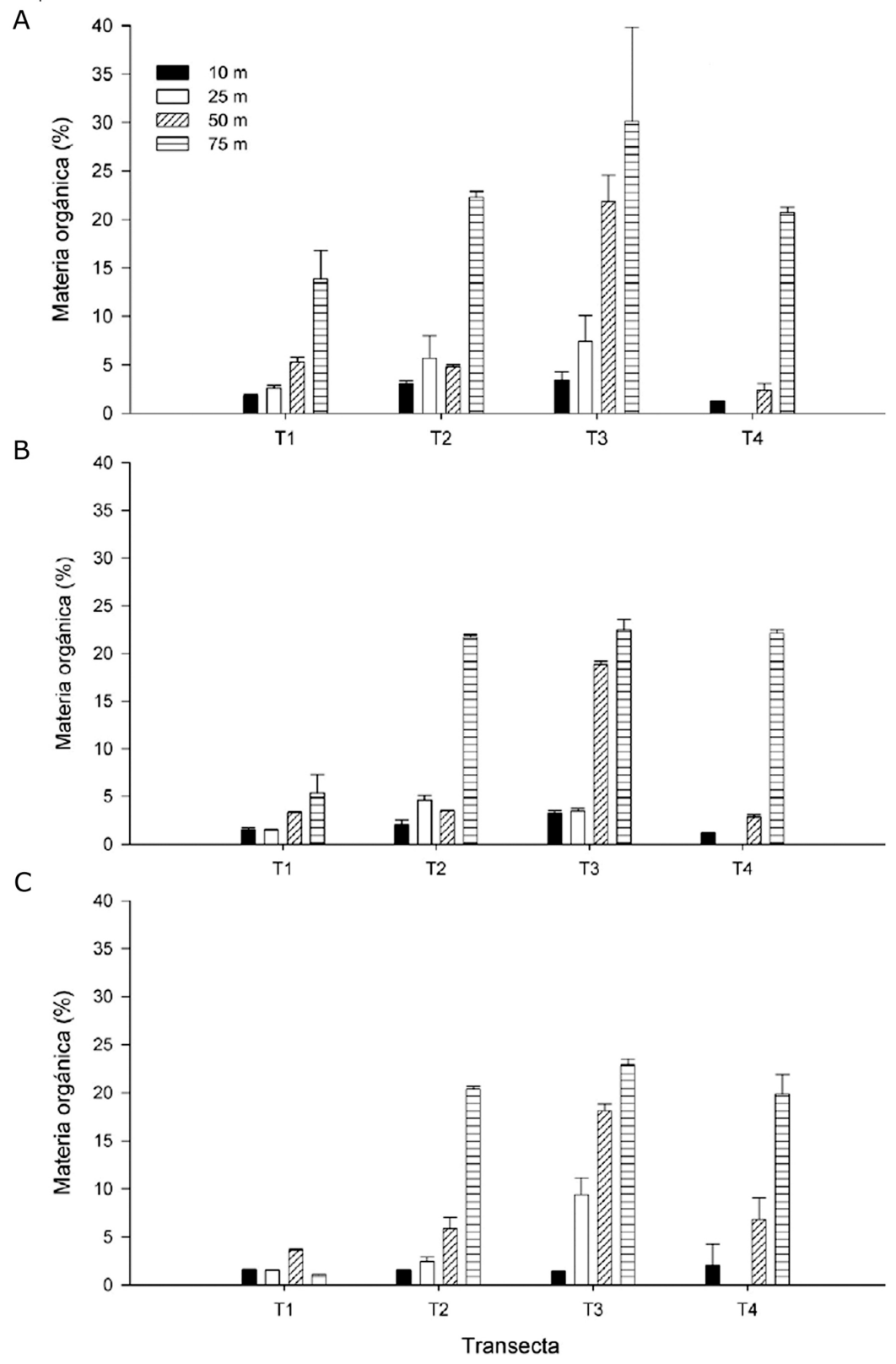

Figura 3. Porcentaje de materia orgánica en los sedimentos recolectados en los transectos en las 3 campañas. A) septiembre 2005, B) diciembre 2005, C) mayo 2006. Los valores representan el promedio del análisis de muestras en triplicado y la desviación estándar / Percentage of organic matter obtained from the 3 sampling periods. A) September 2005, B) December 2006, C) May 2006. Results represent the average of triplicate analyzed samples and standard desviation 

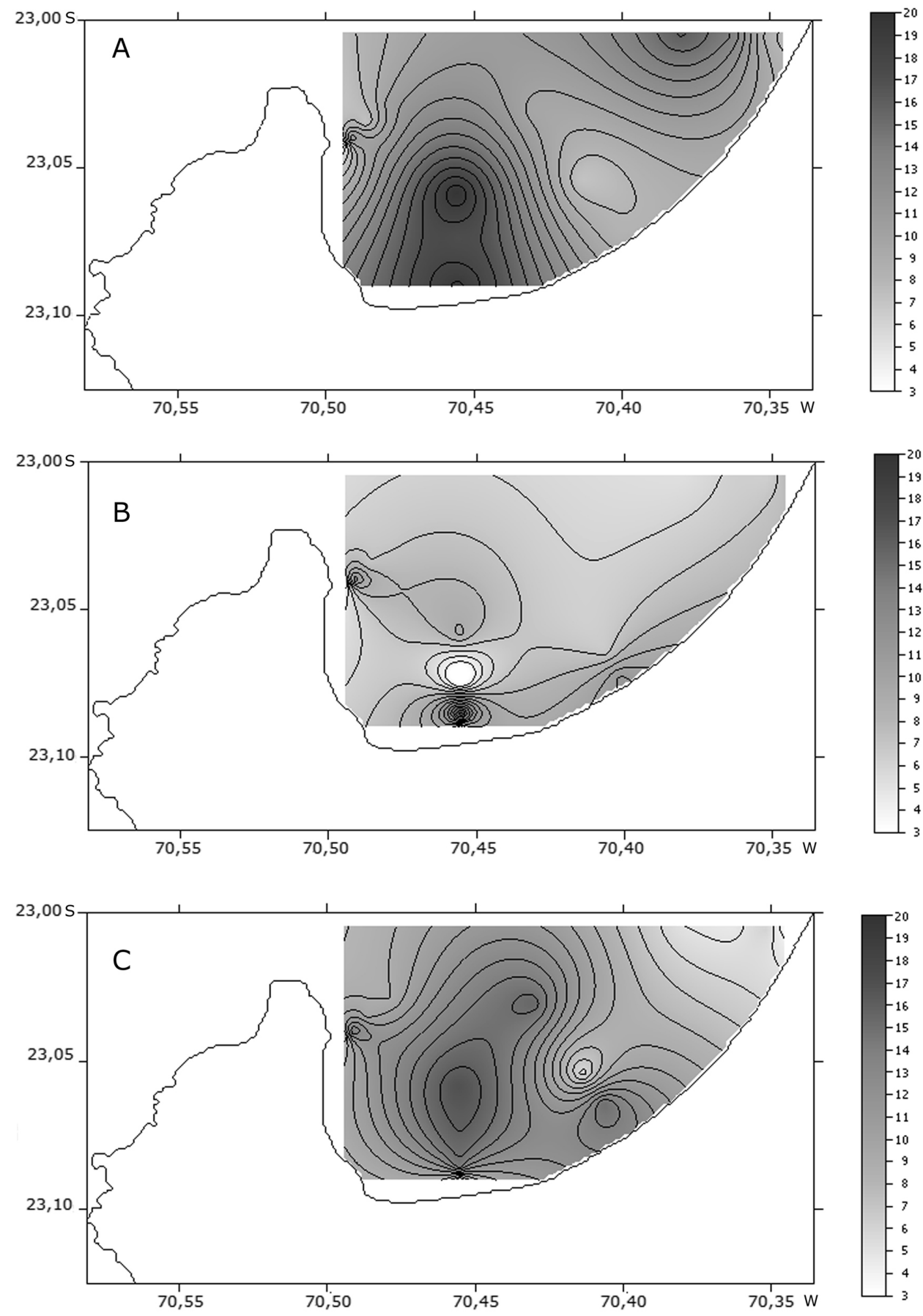

Figura 4. Distribución espacial de los microorganismos en los sedimentos superficiales (recuentos totales por $10^{8}$ cél. $\mathrm{g}^{-1}$ de sedimento). A) septiembre 2005, B) diciembre 2005, C) mayo 2006 / Contour map of microorganism concentration in surface samples (total count per $10^{8}$ cell. $\mathrm{g}^{-1}$ of sediment). A) September 2005, B) December 2006, C) May 2006 


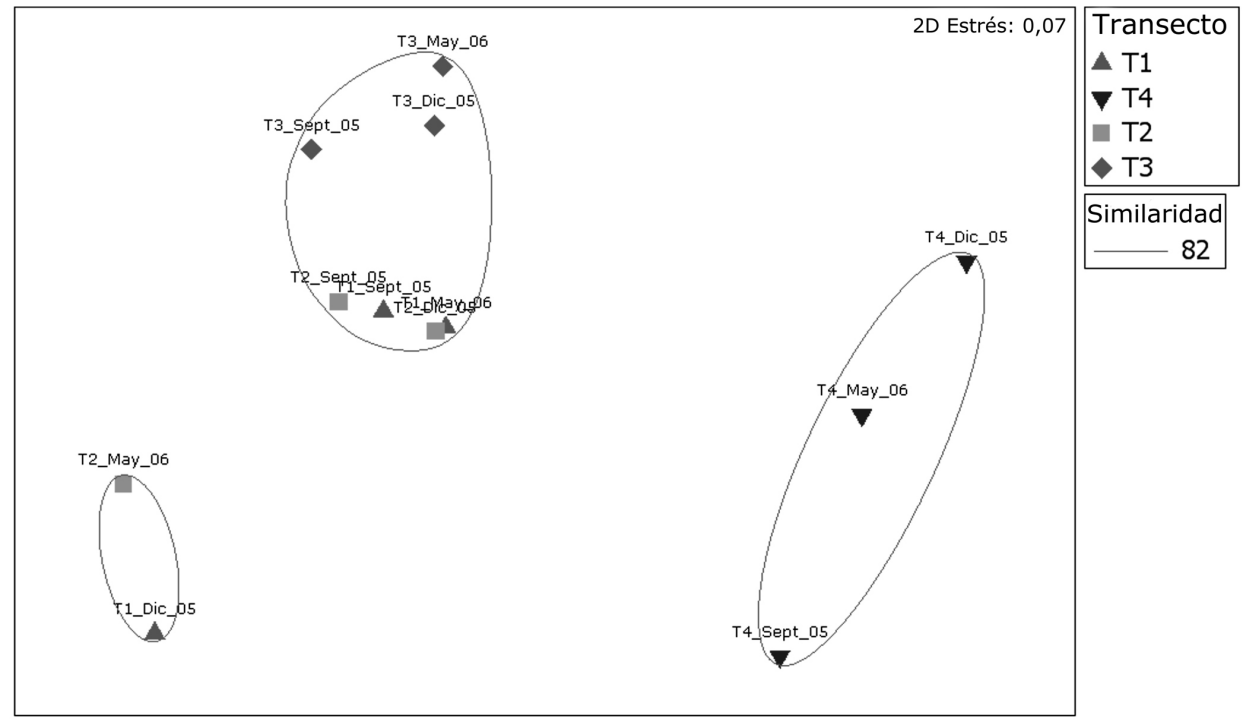

Figura 5. Análisis mediante MDS de los patrones de bandeo obtenidos en los geles de DGGE (a partir del fragmento 16S ADN ribosomal) de las transectos de los 3 periodos estudiados (septiembre 2005, diciembre 2005 y mayo 2006) / MDS analysis from DGGE patterns of transects of the 3 periods studied (September 2005, December 2005 and May 2006)

En este análisis el número de bandas de DGGE (UTO's) fue tomado como un indicador del número de especies en cada muestra. La intensidad relativa de cada banda de DGGE y la sumatoria de todas las intensidades de las bandas dadas para una muestra dada se utilizaron como un estimador de la abundancia de especies (Fromin et al. 2002). La huella digital por DGGE, y otras aproximaciones comunitarias basadas en PCR, sólo indican los organismos dominantes en una muestra. El índice comunitario de diversidad de Shannon $(\mathrm{H})$ y el índice de uniformidad (E) toman en cuenta la intensidad relativa de la UTO's, como una medida de la abundancia de la misma. Ambos índices fueron significativamente diferentes entre los transectos y profundidad (Fig. 6). Para todos los sitios, los valores de diversidad y uniformidad, fueron menores a 1,6 .

Mediante hibridación in situ se analizó la composición de las comunidades microbianas en el sedimento superficial, la cual fue similar en la mayoría de las muestras. No se detectaron cambios significativos en la composición de eubacterias y arqueas en las diferentes profundidades (Fig. 6). Las bacterias anammox no se detectaron con la sonda utilizada. Los resultados obtenidos con FISH permitieron detectar una gran fracción de la comunidad microbiana que habita en los sedimentos de bahía Mejillones. Alrededor de un $70 \%$ de las células teñidas con DAPI hibridizaron con las sondas empleadas en este estudio. La comunidad microbiana analizada fue dominada por Bacteria (Eub mix), donde Arquea (sonda ARCH915) fue detectada en una menor proporción, sobre el limite de detección, fijado en el $1 \%$ de las células teñidas con DAPI.

Con un conjunto de 9 sondas para los phyla principales dentro del dominio bacteria, se pudo afiliar entre el 52 al 90\% del total de células teñidas con DAPI con los grupos bacterianos conocidos. Esto significa que la mayoría de las bacterias detectadas pueden ser afiliadas a un grupo conocido, y entre el 10,5 al 47,4\% del recuento de EUBmix no fue afiliado. El mas abundante grupo filogenético detectado en los sedimentos de bahía Mejillones fue Cytophaga-Flavobacterium, con una abundancia relativa entre 13 a $26 \%$ del recuento de DAPI. La mayoría de las células identificadas dentro de este cluster muestra una morfología homogenea de bacilos largos y finos. Se encontró un número relativamente bajo de procariontes del grupo Proteobacteria ( $\alpha, \beta$ y subclase $\gamma$ ), pero en su conjunto fueron el segundo grupo dominante (9 a 21\%), 

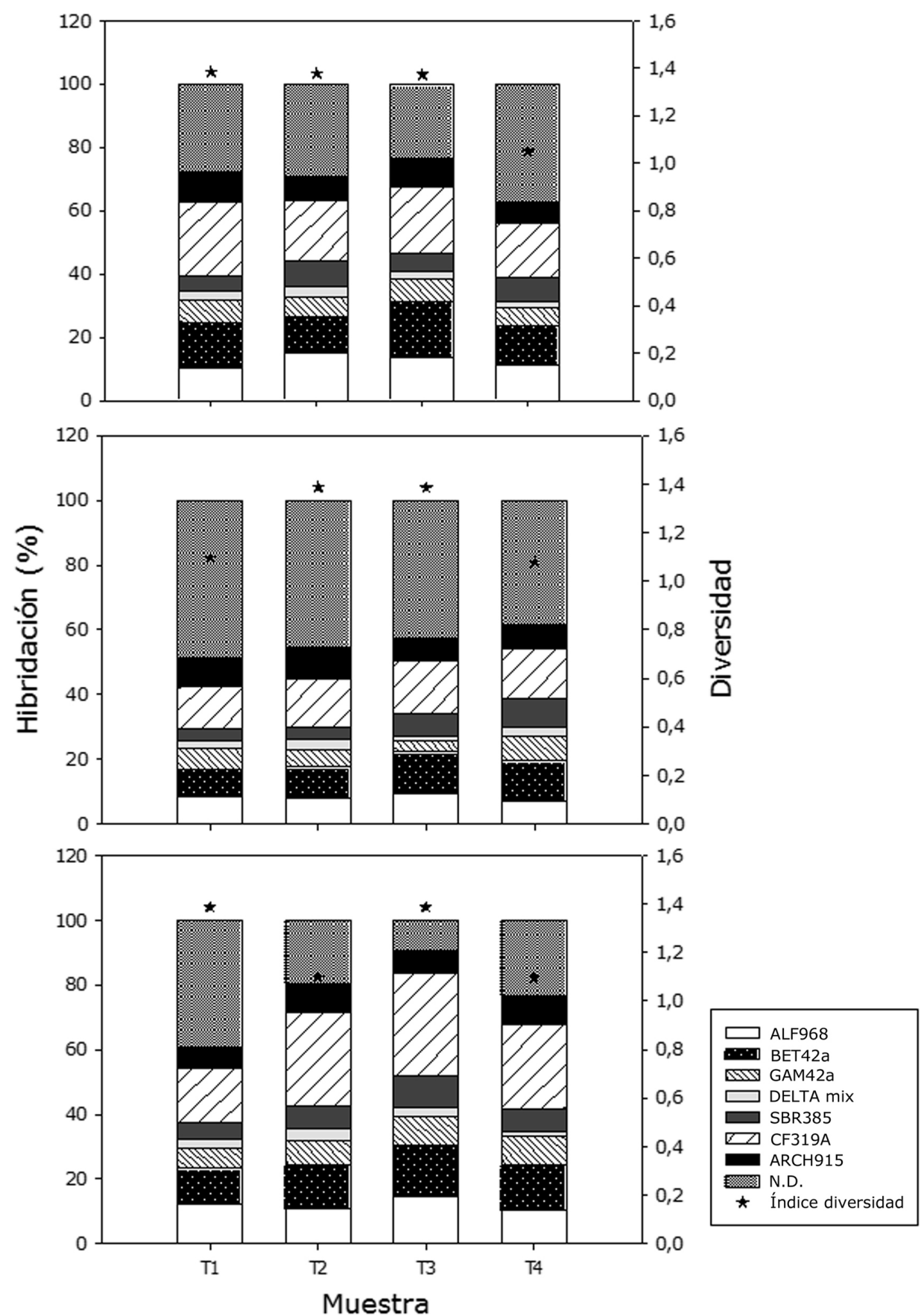

Figura 6. Composición de la comunidad bacteriana expresada como porcentaje del total de la comunidad que hibridizó con las sondas de ARN ribosomal utilizadas en este estudio / Bacterial community composition expressed as a percentage of total community rRNA hybridizing with the probes used in this study 
las bacterias sulfato reductoras, miembros de la subclase $\delta$ de Proteobacteria, se detectaron con la sonda SRB385, con un maximo de $9,8 \%$ y un mínimo de $4,9 \%$ recuento de DAPI. La mayoría de las bacterias desnitrificantes corresponden al grupo de las Proteobacterias.

\section{REMOCIÓN DE NITRÓGENO DESDE SEDIMENTOS POR PROCARIONTES}

La técnica de apereamiento isotópico permite medir simultáneamente los procesos de anammox y desnitrificación, donde la producción $\mathrm{de}^{29} \mathrm{~N}_{2}$ es indicativo de anammox y la produccion de ${ }^{30} \mathrm{~N}_{2}$ es indicativo de desnitrificación. Las incubaciones en condiciones de anoxia de los sedimentos muestran que la producción de ${ }^{15} \mathrm{~N}^{14} \mathrm{~N}$ no fue significativa para ${ }^{15} \mathrm{NH}_{4}^{+}$, y no detectable para ${ }^{15} \mathrm{NO}_{3}^{-}$(Tabla 2). La ausencia y escasa producción de éste, y la acumulación lineal de ${ }^{15} \mathrm{~N}^{15} \mathrm{~N}$ sin una fase de retardo observable, señalan que los trazadores fueron transformados directamente a $\mathrm{N}_{2}$ sin la intervención de intermediarios extracelulares; esto indica que la desnitrificación fue el proceso activo en los sedimentos analizados (Fig. 7). Las tasas para producción de ${ }^{30} \mathrm{~N}$ estuvieron en el rango de 43,31 $\pm 13,16 \mu \mathrm{M} \mathrm{d}^{-1}$ a 111,20 \pm $5,73 \mu \mathrm{M} \mathrm{d}^{-1}$ (Tabla 2).

En el caso del ${ }^{15} \mathrm{NH}_{4}^{+}$no se obtuvo una clara señal con ${ }^{30} \mathrm{~N}$, i.e., evidencia de anammox, por lo que la oxidación anaeróbica del amonio no se observó en los sedimentos analizados. Para el caso del $\mathrm{NO}_{3}^{-}$, la señal de la razón isotópica $\left({ }^{15} \mathrm{~N} /{ }^{14} \mathrm{~N}\right)$ del $\mathrm{T}_{0}$ para este trazador fue muy alta lo que dificultó la posibilidad de un incremento en el tiempo. Para el $\mathrm{NO}_{2}^{-}$se detectó también una importante producción de ${ }^{15} \mathrm{~N}^{15} \mathrm{~N}$ (Fig. 7). Con relación a la remoción de nitrógeno, se identificaron las tasas obtenidas en relación a los trazadores isotópicos.

Tabla 2. Tasas específicas de producción de dinitrógeno determinadas en las incubaciones de los sedimentos superficiales nd $=$ no detectados / Specific production rates dinitrogen in sediment as determined from slurrys incubations $n d=$ non detected

\begin{tabular}{ccc}
\hline Trazador & \multicolumn{2}{c}{$\begin{array}{c}\text { Sedimento } \\
\text { Tasa }\left(\mu \mathrm{M}^{*} \mathrm{~d}^{-1}\right)\end{array}$} \\
\cline { 2 - 3 } & ${ }^{29} \mathrm{~N}$ & ${ }^{30} \mathrm{~N}$ \\
\hline${ }^{15} \mathrm{NO}_{3}{ }^{-}$ & $\mathrm{ND}$ & $111,20135 \pm 5,73$ \\
${ }^{15} \mathrm{NO}_{2}^{-}$ & $21,31 \pm 3,29$ & $43,31009 \pm 13,16$ \\
${ }^{15} \mathrm{NH}_{4}^{+}$ & 0,82 & $\mathrm{ND}$ \\
\hline
\end{tabular}
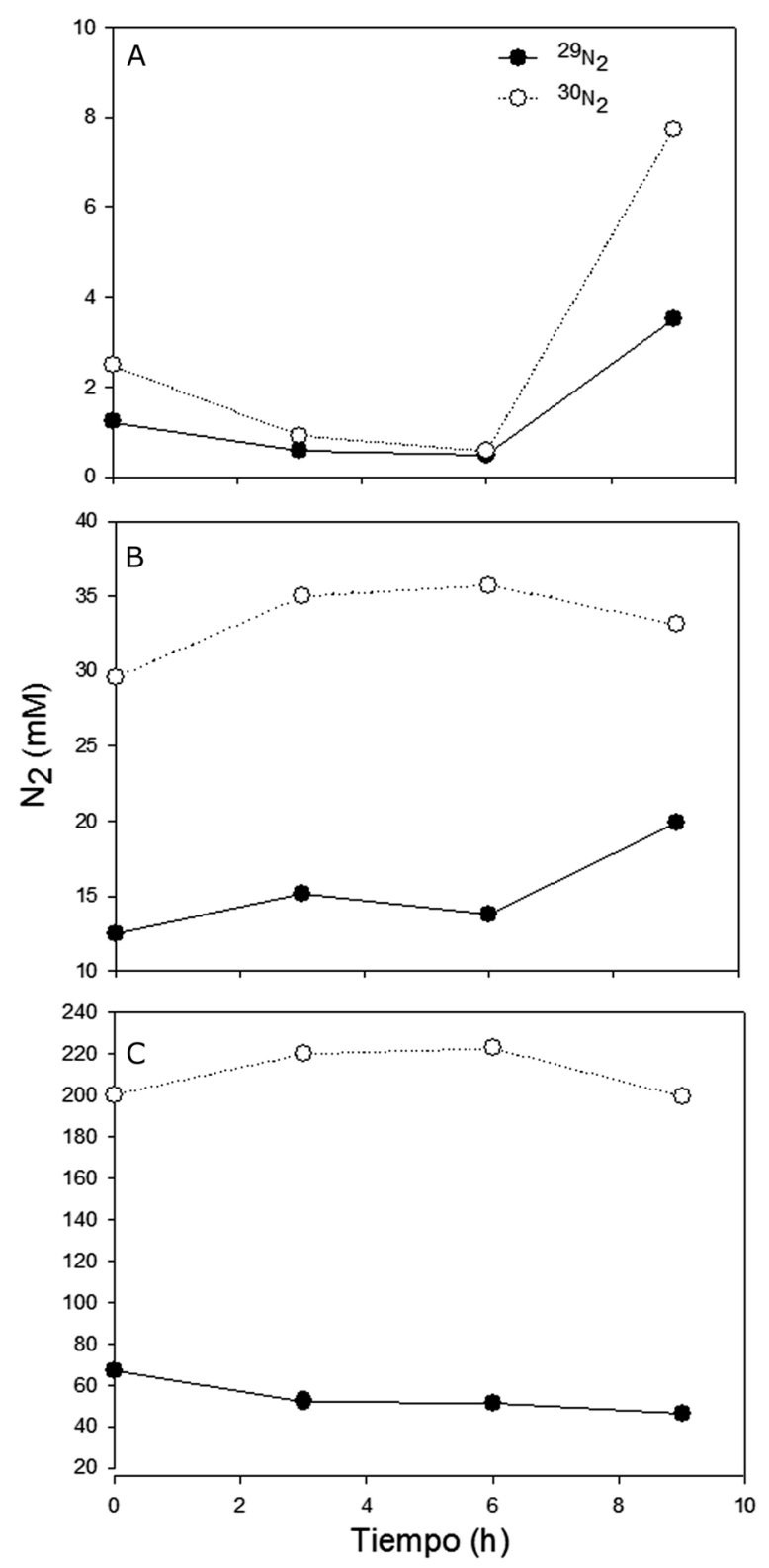

Figura 7. Producción de ${ }^{\times} \mathrm{N}_{2}$ marcado a partir de las incubaciones de los sedimentos superficiales con trazadores. A) Incubación con ${ }^{15} \mathrm{NH}_{4}{ }^{+}$, B) ${ }^{15} \mathrm{NO}_{2}$, C) ${ }^{15} \mathrm{NO}_{3}{ }_{3}^{-}$Production of ${ }^{\times} \mathrm{N}_{2}$ labeled from slurrys incubations. A) Incubation with ${ }^{15} \mathrm{NH}_{4}{ }^{+}$, B) ${ }^{15} \mathrm{NO}_{2}$; C) ${ }^{15} \mathrm{NO}_{3}$.

\section{Discusión}

Letelier et al. (2012) señalaron que la península de Mejillones ejerce una influencia importante en la variabilidad oceanográfica entre $\operatorname{los} 22^{\circ}$ y $24^{\circ} \mathrm{S}$, siendo más que un accidente topográfico, la península impacta en la distribución espacial de vientos y corrientes, como 
también refuerza la surgencia costera y los flujos que rodean la península al modificar la distribución latitudinal del transporte de Ekman o específicamente el rotor del estrés del viento. Esta situación, que se extiende hacia bahía Mejillones, da cuenta de las condiciones hidrodinámicas particulares que le permiten ser un centro de depositación sedimentaria, situación señalada por Cerda et al. (2010) quienes sugieren que la sedimentación del material en la columna de agua se encuentra gobernada por la alternancia entre los períodos de surgencia y de estratificación. Por otra parte, Guiñez et al. (2010) indicaron para el área de estudio, que la variabilidad espacial de la ZMO genera diferencias significativas en la composición de la materia orgánica, y que entre los factores más importantes que afectan a los procesos degradativos son la profundidad y la concentración de oxígeno disuelto, por lo tanto el material orgánico contenido en los sedimentos de mayor profundidad presentan una mayor preservación debido al efecto de la ZMO.

Este hecho permite relacionar la contribución de la comunidad microbiana en la degradación de la materia orgánica, es decir relaciona la disponibilidad de materia orgánica y carbono, las cuales se incrementan en las aguas de fondo durante los períodos cálidos debido a la precipitación de los productos del fitoplancton originado en las aguas superficiales de la bahía (Valdés et al. 2009). Sin embargo, a pesar de este fenómeno característico de los periodos cálidos, el afloramiento de aguas ricas en nutrientes que se caracterizan por condiciones de suboxia y microxia, se traducen en una limitación para la descomposición de la materia orgánica en la columna de agua, lo que ayudaría a su depósito en los sedimentos del piso de la bahía (Caniupán et al. 2009). Por otra parte, los mayores valores de $\mathrm{MO}$ en el área de estudio se observaron en los sectores T2 y T3, lo cual probablemente se asocie a su ubicación en el área de influencia urbana en la bahía y a la actividad de desembarque de la actividad pesquera local. Estos resultados permiten sugerir que la zona urbana localizada frente a T3 tendría una mayor injerencia sobre la composición biogénica de los sedimentos de fondo de la bahía (Valdés et al. 2009).

La contribución de materia orgánica y de nutrientes incidiría en la producción secundaria observada, lo cual es concordante con las altas concentraciones de clorofila presente durante todo el año en la bahía debido al efecto topográfico, forma y orientación de la bahía que retienen las aguas surgentes al interior de esta (Letelier et al. 2012). Esto permitiría sostener que estos factores serían los responsables en gran medida de sustentar a las poblaciones baterianas en los sedimentos estudiados.

Los analisis de la comunidad microbiana presente en los sedimentos mediante DGGE, revelaron una alta presencia de UTO's, las bandas de DGGE son consideradas como secuencias únicas (UTO's) dentro de las limitaciones impuestas por la PCR (Fromien et al. 2002, Torsvik et al. 2002); éstas oscilaron entre 7 y 32 bandas por transecto. Se asume que representan el $10 \%$ de las especies presentes (Torsvik et al. 2002), entonces solo cerca de 70 a 320 especies fueron representadas en cualquier muestra. Este número de especies es bajo si se compara con otros ambientes. Sin embargo, es comparable a reportes de ambientes acuaticos o sedimentos con cierto impacto ambiental (Freitag et al. 2003, Haack et al. 2004). Para la ecologia de macroorganismos, los índices permiten a la comunidad ser comparada mediante su diversidad, número de especies, uniformidad o dominancia. En la actualidad, es de gran interes definir estos parámetros en las comunidades microbianas (Torsvik et al. 2002). Los sedimentos son ambientes químicamente complejos, con muchos gradientes diferentes de concentración de sustrato, $\mathrm{pH}$, potencial redox, los cuales contribuyen a la conformación de un gran número de microhábitats, que pueden generar una enmarañada diversidad microbiana. Por otra parte, las perturbaciones ambientales, dependiendo de su intensidad y extensión pueden llevar a la disminución de la diversidad local conduciendo a la proliferación de poblaciones adaptadas que pasan a ser dominantes (Torsvik et al. 2002).

En el contexto de la hipótesis de perturbación intermedia (Connell 1978), Buckling et al. (2000) y Cadotte (2007) indicaron que niveles intermedios de perturbación generan a una mayor diversidad, lo cual requiere para la coexistencia de las especies un equilibrio entre la capacidad competitiva y la tolerancia a las perturbaciones. Para el área de estudio, Araya et al. (2008) señalaron que los sedimentos marinos de bahía Mejillones presentaron una alta diversidad procariota, lo cual estaría influenciado por cambios en los patrones de circulación al interior de la bahía, esto es congruente con lo observado en relación a la diversidad de los transectos estudiados. Cerda et al. (2010), Guiñez et al. (2010) y Letelier et al. (2012), sostienen que las masas de aguas provenientes de los focos de surgencia ingresan a la bahía por el margen noroeste desde Punto Chacaya (T1) hasta Capitania de Puerto (T3), con un giro ciclonico en Punta Chacaya, lo cual origina una mezcla en la columna de agua. Punta de Rieles (T4) se caracteriza por presentar pulsos de afloramientos, los cuales ingresan por Punta Angamos, siendo importantes 
en el inicio de primavera (Marín \& Olivares 1999). Estos patrones de circulación influyen en la dinámica interna de la bahía e impactan en la estructura de las comunidades procariotas.

En cuanto a los resultados obtenidos mediante FISH, se puede mencionar para el dominio Arquea, los porcentajes de hibridación fueron bajos en relación a otros estudios moleculares en ambientes marinos y no marinos, donde se indicaron una mayor abundancia (Ravenschlag et al. 2001, Haack et al. 2004, Maturrano et al. 2006, Molari \& Manini 2012). Es probable que un gran número de células no sean detectadas por FISH, pero no se puede excluir la posibilidad que arquea forme parte de las células teñidas con DAPI que no hibridicen con la sonda ARCH915 (Pernthaler et al. 2002). El número relativamente bajo de los miembros de $\alpha$-Proteobacteria en los sedimentos fue inesperado, ya que se han descrito como un grupo predominante en el plancton marino (LloberBrossa et al. 1998). Stevens \& Ulloa (2008) señalaron para la ZMO del norte de Chile, una comunidad diversa y distinta en funcion de la profundidad, las mayoría de las secuencias fueron afiliadas a gamma $(53,7 \%) \mathrm{y}$ $\alpha$-Proteobacteria (19,7\%), y Bacteroidetes $(11,2 \%)$. En la ZMO los principales constituyentes fueron afiliados al clado marino SAR11 y a oxidadores del azufre $\gamma$-simbiontes, grupo no comúnmente asociados a aguas pelágicas, también fueron afiliados al phylum Chloroflexi, a los clados AGG47 y SAR202, $\delta$-Proteobacteria, Acidobacteria, el grupo anammox de Plantomycetes fue exclusivo de la ZMO. Por otra parte, Steward et al. (2012), en un estudio de metatranscriptomica para la misma zona en estudio, cuya caracterización se basó en BLAST de secuencias de ARN no ribosomal, revelaron un predominio de genes involucrados en los procesos oxidativos (nitrificación) y de reducción (anammox, desnitrificación), ambos componentes del ciclo del nitrógeno marino.

En general, estos resultados señalan que la estructura comunitaria en los sedimentos difieren significativamente de la que se encuentra en la capa superior de la columna de agua de esta bahía. El cluster CytophagaFlavobacterium fue el grupo mayoritario, que se ha encontrado como un constituyente principal de las comunidades microbianas unidas a macroagregados en los ambientes marinos (DeLong et al. 1994). Estudios recientes (Ganesh et al. 2014), señalan la importancia de los microagregados como partículas, cuya superficie pueden convertirse en focos para el intecambio genómicos de los microrganismos marinos, mediante mecanismos de transferencia horizontal de genes. En su estudio en el norte de Chile, encontraron para la fracción $>1,6 \mu \mathrm{m}$ de la comunidad microbiana un enriquecimiento significativo de sus genes mediante interacciones sociales, poniendo de manifiesto el importante papel para la fijación que juega una superficie en la formación del potencial metabólico de la comunidad y del genoma contenido en los microorganismos de la ZMO, donde los genes para la reducción del óxido nítrico y nitroso fueron de 3 a 7 veces más abundantes. Esto sugiere que los micronichos son compartimentos claves para los pasos de la desnitrificación. Cabe señalar que la desnitrificación es un proceso anaerobio llevado a cabo por microorganismos filogenéticamente distintos de grupos de bacterias y arqueas, dentro de las cuales algunos grupos estan afiliadas a las Proteobacterias, dentro de estas a la subclase $\gamma$, en cambio el proceso de anammox es restingido a un grupo de microorganismos quimiolitotrofos pertenecientes al Phylum Planctomycetes.

En general, los resultados de hibridación son semejantes a los obtenidos en otros estudios para agua de mar, sedimentos y suelos (Zarda et al. 1997, LlobetBrossa et al. 1998, Ravenschlag et al. 1999, 2000; Galan et al. 2009, Molari \& Manini 2012).

En los resultados obtenidos se evidencia una alta actividad desnitrificante en los sedimentos (43,31-111,20 $\mu \mathrm{M} \mathrm{d}^{-1}$ ); en estudios reportados para el bentos del mar de Arabia, Sokoll et al. (2012), encontraron que los procesos de desnitrificacion son importantes en los sedimentos costeros bajo influencia de la ZMO, con tasas de 1,46$2,73 \mathrm{mM} \mathrm{m}^{-2} \mathrm{~d}^{-1}$, y en sedimentos más profundos los procesos anammox son los preponderantes. Para esa misma zona, Ward et al. (2009) indicaron que la desnitrificación es el proceso dominante en los experimentos de apareamiento isotópico realizados con muestras de agua de la ZMO $\left(0,24-25,4 \mathrm{nM} \mathrm{d}^{-1}\right)$; reportes previos para la zona norte de Chile (Castro-González \& Farias 2004), frente a las costas de Antofagasta señalaron tasas de desnitrifación en la columna de agua de $2,4 \mu \mathrm{M}$ $\mathrm{d}^{-1}$. Los resultados son concordantes con lo señalado Thamdrup \& Dalsgaard (2002), Thamdrup et al. (2006), y Ward et al. (2009), quienes indican que la remocion del $\mathrm{N}$ fijado en los ambientes marinos ocurre preferentemente en sedimentos y en aguas subóxicas, y que los sedimentos son responsables de 2/3 de la remoción de la producción total de $\mathrm{N}_{2}$, (Dalsgaard et al. 2003, 2005). Por otra parte, Engström et al. (2005), y Dalsggard et al. (2005), sostienen que las comunidades microbianas desnitrificantes tienen una tasa de crecimiento mucho mayor que las bacterias anammox, lo cual les da una ventaja competitiva en estos 
ambientes fluctuantes, como es el caso de bahía Mejillones. Cerda et al. (2010) observaron en estas aguas un patrón de empobrecimiento del nitrógeno inorgánico disuelto en función de la profundidad, esto sugeriría condiciones de remineralización y desnitrificación en las aguas de fondo de esta bahía, lo cual es concordante con la información obtenida en este estudio y con reportes previos para la zona (Castro-González \& Farías 2004). Se detecto una fuerte producción de $\mathrm{N}_{2} \mathrm{O}$ en el límite superior de la ZMO (datos no mostrados), lo que daría cuenta de una actividad desnitrificante y también de procesos de nitrificación.

Farías et al. (2007) indican que la alta acumulación de este gas puede perderse hacia la atmósfera contribuyendo al efecto invernadero o ser utilizado como una fuente de aceptor de electrones en la ZMO para la actividad de desnitrificación. Castro-González \& Farías (2004) reportan para la zona norte de Chile (Iquique-Antofagasta) que la producción de $\mathrm{N}_{2} \mathrm{O}$ fue en un $92 \%$ generada por los procesos de desnitrificación y que $\sim 100 \%$ de esta producción fue utilizada por este proceso.

Los resultados obtenidos permiten discernir y sostener lo que sucede en el periodo en estudio, en ese aspecto los procesos de desnitrificación fueron los que se detectaron como principal responsable de la remoción de $\mathrm{N}_{2}$, esto asociados a la presencia de ciertos clados de Proteobacteria. No obstante, según lo reportado en la literatura para la zona norte de Chile (i.e., Iquique y Antofagasta), no se descarta la ocurrencia de procesos de anammox en la zona de estudio. Los resultados de este trabajo respaldan la importancia de los procesos de desnitrificación en los sedimentos de aguas someras bajo la influencia de la ZMO, como es el caso de bahía Mejillones, los cuales deben ser analizados con mesura, ya que existen interrogantes que se deben dilucidar y con probables implicancias ecológicas dado el tipo de compuesto que se libera a la atmósfera.

\section{Agradecimientos}

Esta investigación fue financiada a través de las becas de apoyo a la realización de tesis doctoral de CONICYT, PAT 24090043 y por el Proyecto DI 0002-08, de la Dirección de Investigación de la Universidad Arturo Prat.

\section{LiTERATURA CITADA}

Amann RI, BJ Binder, RJ Olson, SW Chisholm, R Devereux \& DA Stahl. 1990. Combination of 16S rRNAtargeted oligonucleotide probes with flow cytometry for analyzing mixed microbial populations. Applied and Environmental Microbiology 56: 1919-1925.

Araya R, JC Leiva \& J Valdés. 2008. Caracterización molecular de las comunidades bacterianas asociadas a sedimentos de un sistema costero del norte de la corriente de Humboldt, bahía de Mejillones del Sur, Chile. Revista de Biología Marina y Oceanografía 43: 547-557.

Arrigo K. 2005. Marine microorganisms and global nutrient cycles. Nature 437: 349-355.

Barber R \& R Smith. 1981. Coastal upwelling ecosystems. In: Longhurst A (ed). Analysis of marine ecosystems, pp. 31-68. Academic Press, New York.

Bray JR \& JT Curtis. 1975. An ordination of the upland forest communities of southern Wisconsin. Ecological Monographs 27: 325-349.

Buckling A, R Kassen, G Bell \& PB Rainey. 2000. Disturbance and diversity in experimental microcosms. Nature 408: 961-964.

Cadotte MW. 2007. Competition-colonization trade-offs and disturbance effects at multiple scales. Ecology 88(4): 823-829.

Caniupán M, T Villaseñor, S Pantoja, C Lange, G Vargas, P Muñoz \& M Salamanca. 2009. Sedimentos laminados de la Bahía Mejillones como registro de cambios temporales en la productividad fitoplanctónica de los últimos $\sim 200$ años. Revista Chilena de Historia Natural 82: 83-96.

Capone D \& D Hutchins. 2013. Microbial biogeochemistry of coastal upwelling regimes in a changing ocean. Nature Geoscience 6: 711-717.

Castro-González M \& L Farías. 2004. $\mathrm{N}_{2} \mathrm{O}$ cycling of the core of the oxygen minimum zone off northern Chile. Marine Ecology Progress Series 280: 1-11.

Cerda M, B Knoppers, J Valdés, A Siffedine, L Ortlieb \& E Sabadini-Santos. 2010. Variación espacial y temporal de las masas de agua, nutrientes y sedimentación de la materia orgánica e inorgánica en la bahía Mejillones del sur $\left(23^{\circ} \mathrm{S}\right)$, Chile. Revista Chilena de Historia Natural 83: 409-420.

Codispoti L. 1995. Is the ocean loosing nitrate? Nature 376: 724.

Connell JH. 1978. Diversity in tropical rain forests and coral reefs. Science 199: 1302-1310.

Daims H, A Brühl, R Amann, K-H Schleifer \& M Wagner. 1999. The domain-specific probe EUB338 is insufficient for the detection of all Bacteria: Development and evaluation of a more comprehensive probe set. Systematic and Applied Microbiology 22: 434-444.

Dalsgaard T \& B Thamdrup. 2002. Factors controlling anaerobic ammonium oxidation with nitrite in marine sediments. Applied and Environmental Microbiology 68: 3802-3808. 
Dalsgaard T, DE Canfield, J Petersen, B Thamdrup \& J Acuña-González. 2003. $\mathrm{N}_{2}$ production by the anammox reaction in the anoxic water column of Golfo Dulce, Costa Rica. Nature 422: 606-608.

Dalsgaard T, B Thamdrup \& DE Canfield. 2005. Anaerobic ammonium oxidation (anammox) in the marine environment. Research in Microbiology 156: 457-464.

Dalsgaard T, B Thamdrup, L Farias \& NP Revsbech. 2012. Anammox and denitrification in the oxygen minimum zone of the eastern South Pacific. Limnology and Oceanography 57: 1331-1346.

DeLong EF, DG Franks \& AL Alldredge. 1993. Phylogenetic diversity of aggregate-attached $v s$. free-living marine bacterial assemblages. Limnology and Oceanography 38: 924-934.

Engström P, T Dalsgaard, S Hulth \& RC Aller. 2005. Anaerobic ammonium oxidation by nitrite (anammox): Implications for N2 production in coastal marine sediments. Geochimica et Cosmochimica Acta 69(8): 2057-2065.

Farías L, A Paulmier \& M Gallegos. 2007. Nitrous Oxideand N-nutrient cycling in the oxygen minimum zone off northern Chile. Deep-Sea Research Part I 54: 164-180.

Farías L, M Castro-González, M Cornejo, J Charpentier \& J Faúndez. 2009. Denitrification and nitrous oxide cycling within the upper oxycline of the Eastern tropical South Pacific oxygen minimum zone. Limnology and Oceanography 54: 132-144.

Freitag TE, T Klenke, WE Krumbein, G Gerdes \& JI Prosner. 2003. Effect of anoxia and high sulphide concentrations on heterotrophic microbial communities in reduced surface sediments (Black Spots) in sandy intertidal flats of the German Wadden Sea. FEMS Microbiology Ecology 44: 291-301.

Fromin N, J Hamelin, S Tarnawski, D Roesti, K JourdainMiserez \& N Forestier. 2002. Statistical analysis of denaturing gel electrophoresis (DGE) fingerprinting patterns. Environmental Microbiology 4: 634-643.

Galan A, V Molina, B Thamdrup, D Woebken, G Lavik, M Kuypers \& O Ulloa. 2009. Anammox bacteria and the anaerobium oxidation ammonium in the oxygen minimum zone off northern Chile. Deep-Sea Research Part II 56: 1021-1031.

Ganesh S, DJ Parris, EF DeLong \& FJ Steward.2014. Metagenomic analyses of size-fractionated picoplankton in a marine oxygen minimum zone. ISME Journals 8: 187211.

Guiñez M, J Valdés \& A Sifeddine. 2010. Variabilidad espacial y temporal de la materia orgánica sedimentaria, asociada a la Zona de Mínimo Oxígeno (ZMO), en un ambiente costero del norte de la corriente de Humboldt, bahía de Mejillones, Chile. Latin American Journal of Aquatic Research 38(2): 242-253.
Haack SK, LR Fogarty, TG West, EW Alm, JT McGuire, DT Long, DW Hyidman \& LJ Forney. 2004. Spatial and temporal changes in microbial community structure associated with recharge-influenced chemical gradients in a contaminated aquifer. Environmental Microbiology 6(5): 438-448.

Hamersley MR, G Lavik, G Woebken, JE Rattray, P Lam, EC Hopmans, JS Sinninghe, S Krüge, M Graco, D Gutiérrez \& MM Kuypers. 2007. Anaerobic ammonium oxidation in the Peruvian OMZ. Limnology and Oceanography 52: 923-933.

Ishii M, B Mussmann, J MacGregor \& R Amann. 2004. An improved fluorescence in situ hybridization protocol for the identification of bacteria and archaea in marine sediments. FEMS Microbiology Ecology 50: 203-212.

Iwamoto T, K Tani, K Nakamura, Y Suzuki, M Kitagawa, M Eguchi \& M Nasu. 2000. Monitoring impact of in situ biostimulation treatment on groundwater bacterial community by DGGE. FEMS Microbiology Ecology 32: 129-141.

Kuypers M, AO Sliekers, G Lavik, M Schmid, B Jørgensen, JG Kuenen, JS Damsté, M Strous \& M Jetten. 2003. Anaerobic ammonium oxidation by anammox bacteria in the Black Sea. Nature 422: 608-611.

Letelier J, L Soto-Mardones, S Salinas, L Vincenti, R Pavez \& M Arriagada. 2012. Influencia de la península de Mejillones en la variabilidad oceanográfica anual e interanual frente al norte de Chile. Revista de Biología Marina y Oceanografía 47(3): 513-526.

Llobet-Brossa E, R Rosselló-Mora \& R Amann. 1998. Microbial community composition of Wadden Sea sediments as revealed by fluorescence in situ hybridization. Applied and Environmental Microbiology 64(7): 26912696.

Loy A, A Lehner, N Lee, J Adamczyk, H Meier, J Ernst, KH Schleifer \& M Wagner. 2002. Oligonucleotide microarray for $16 \mathrm{~S}$ rRNA gene-based detection of all recognized lineages of sulfate-reducing prokaryotes in the environment. Applied and Environmental Microbiology 68: 5064-5081.

Lücker S, D Steger, KU Kjeldsen, BJ MacGregor, M Wagner \& A Loy. 2007. Improved 16S rRNA-targeted probe set for analysis of sulfate-reducing bacteria by fluorescence in situ hybridization. Journal of Microbiological Methods 69: 523-528.

Manz W, R Amann, W Ludwig, M Wagner \& K-H Schleifer. 1992. Phylogenetic oligodeoxynucleotide probes for the major subclasses of Proteobacteria: problems and solutions. Systematic. Applied Microbiology 15: 593-600.

Manz W, R Amann, W Ludwig, M Vancanneyt \& KH Schleifer. 1996. Application of a suite of $16 \mathrm{~S}$ rRNAspecific oligonucleotide probes designed to investigate bacteria of the phylum cytophaga-flavobacter-bacteroides in the natural environment. Microbiology 142: 1097-1106. 
Marín V \& G Olivares. 1999. Estacionalidad de la productividad primaria en bahía Mejillones del Sur (Chile): una aproximación proceso-funcional. Revista Chilena de Historia Natural 72: 629-641.

Maturrano L, F Santos, R Rosello-Mora \& J Anton. 2006. Microbial diversity in Maras Salterns, a hypersaline environment in the Peruvian Andes. Applied and Environmental Microbiology 72(6): 3887-3895.

Middelburg J, K Soetaert, P Hermann \& C Heip. 1996. Denitrification in marine sediments: A model study. Global Biogeochemical Cycles 10: 661-673.

Molari M \& E Manini. 2012. Reliability of CARD-FISH procedure for enumeration of Archaea in deep-sea surficial sediments. Currents Microbiology 64(3): 242-250.

Morales C, S Hormazábal \& JL Blanco. 1999. Interanual variability in the mesoscale distribution of the depth of the upper boundary of the oxygen minimum layer off northern Chile (18-24 $\left.{ }^{\circ} \mathrm{S}\right)$ : Implications for the pelagic system and biogeochemical cycling. Journal of Marine Research 57: 909-932.

Mulder A, AA Van de Graff, LA Robertson \& JG Kuenen. 1995. Anaerobic ammonium oxidation discovered in a denitrifying fluidized bed reactor. FEMS Microbial Ecology 16: $177-184$.

Myers RM, SG Fischer, LS Leman \& T Maniatis. 1985. Nearly all single base substitutions in DNA fragments joined to a GCclamp can be detected by denaturing gradient gel electrophoresis. Nucleic Acids Research 13: 3131-3145.

Nelson DW \& LE Sommers. 1982. Total organic carbon and organic matter. In: Page AL, RH Miller \& DR Keeney (eds). Method of soil analysis. Part. 2: 539-579. American Society of Agronomy, Madison.

Pernthaler A, J Pernthaler \& R Amann. 2002. Fluorescence in situ hybridization and catalyzed reporter deposition for the identication of marine bacteria. Applied and Environmental Microbiology 68: 3094-3101.

Pielou EC. 1966. The measurement of diversity in different types of biological collections. Journal of Theoretical Biology 13: 131-144.

Rabus R, M Fukui, H Wilkes \& F Widdle. 1996. Degradative capacities and 16S rRNA-targeted whole-cell hybridization of sulfate-reducing bacteria in an anaerobic enrichment culture utilizing alkylbenzenes from crude oil. Applied and Environmental Microbiology 62: 3605-3613.

Ravenschlag K, K Sahm, J Pernthaler \& R Amman. 1999. High bacterial diversity in permanently cold marine sediments. Applied and Environmental Microbiology 65: 3982-3989.

Ravenschlag K, K Sahm, C Knoblauch, B Jorgensen \& R Amman. 2000. Community structure, cellular RNA content and activity of sulfate-reducing bacteria in marine Artic sediments. Applied and Environmental Microbiology 66: 3592-3602.
Ravenschlag K, K Sahm \& R Amman. 2001. Quantitative molecular analysis of the microbial community in marine Artic sediments. Applied and Environmental Microbiology 67: 387-395.

Rochelle P, B Crag, J Fry, R Parkes \& J Weightman. 1994. Effect of sample handling on estimation of bacterial diversity in marine sediments by $16 \mathrm{~S}$ rRNA gene sequence analysis. FEMS Microbiology Ecology 15: 215-226.

Rodríguez L \& R Escribano. 1996. Bahía de Antofagasta y bahía de Mejillones del Sur: observaciones de la temperatura, penetración de la luz, biomasa y composición fitoplanctónica. Estudios Oceanológicos 15: 75-85.

Rysgaard S, R Nøhr, N Risgaard-Petersen \& T Dalsgaard. 2004. Denitrification and anammox activity in Arctic marine sediments. Limnology and Oceanography 49(5): 1493-1502.

Shannon CE \& W Weaver. 1963. The mathematical theory of communication, $144 \mathrm{pp}$. University of Illinois Press, Urbana.

Snaidr J, R Amann, I Huber, W Ludwig \& KH Schleifer. 1997. Phylogenetic analysis and in situ identification of bacteria in activated sludge. Applied and Environmental Microbiology 63: 2884-2896.

Sokoll S, M Holtappels, P Lam, G Collins, M Schlüter, G Lavik \& M Kuypers. 2012. Benthic nitrogen loss in the Arabian Sea off Pakistan. Frontiers in Microbiology 3: 395. <doi:10.3389/fmicb.2012.00395>.

Stahl DA \& R Amann. 1991. Development and application of nucleic acid probes. In: Stackebrandt E \& M Goodfellow (eds). Nucleic acid techniques in bacterial systematics, pp. 205-248. John Wiley \& Sons, Chichester.

Stevens H \& O Ulloa. 2008. Bacterial diversity in oxygen minimum zone of the eastern tropical South Pacific. Environmental Microbiology 10(5): 1244-1259.

Steward F, O Ulloa \& EF Delong. 2012. Microbial metatranscriptomics in a permanent marine oxygen minimum zone. Environmental Microbiology 14: 23-40.

Strub P, J Mesías, V Montecino, J Rutllant \& S Salinas. 1998. Coastal ocean circulation off western South America, coastal segment. In: Robinson AR \& KH Brink (eds). The Sea 11: 273-313. John Wiley \& Sons, New York.

Thamdrup B \& T Dalsgaard. 2002. Production of $\mathrm{N}_{2}$ through anaerobic ammonium oxidation coupled to nitrate reduction in marine sediments. Applied and Environmental Microbiology 68(3): 1312-1318.

Thamdrup B, M Jensen, T Dalsgaard, O Ulloa, L Farías \& R Escribano. 2006. Anaerobic ammonium oxidation in the oxygen-deficient water off northern Chile. Limnology and Oceanography 51: 2145-2156.

Tiquia S, S Masson \& A Devol. 2006. Vertical distribution of nitrite reductase genes (nirS) in continental margin sediments of the Gulf of Mexico. FEMS Microbiology Ecology 58: 464-475. 
Torsvik V, L Øverås \& TF Thingstad. 2002. Prokaryotic diversity-magnitude, dynamics and controlling factors. Science 296: 1064-1066.

Ulloa O, R Escribano, S Hormazabal, R Quiñónez, R González \& M Ramos. 2001. Evolution and biological effects of the 1997-98 El Niño in the upwelling ecosystem off northern Chile. Geophysical Research Letters 28: 15911594.

Valdés J. 2004. Evaluación de metales redox-sensitivos como proxies de paleoxigenación en un ambiente marino hipóxico del norte de Chile. Revista Chilena de Historia Natural 77: 121-138.

Valdés J, L Ortlieb \& A Sifeddine. 2003. Variaciones del sistema de surgencia de Punta Angamos $\left(23^{\circ} \mathrm{S}\right)$ y la Zona de Mínimo Oxígeno durante el pasado reciente. Una aproximación desde el registro sedimentario de la Bahía Mejillones del Sur. Revista Chilena de Historia Natural 76: 347-362.
Valdés J, D Román, P Dávila, L Ortlieb \& M Guíñez. 2006. Variabilidad estacional de cadmio en un sistema de surgencia costera del norte de Chile (Bahía Mejillones del Sur, 23ํㅇ). Revista Chilena de Historia Natural 79: 517-535.

Wallner G, R Amann \& W Beisker. 1993. Optimizing fluorescent in situ hybridization with rRNA-targeted oligonucleotide probes for flow cytometric identification of microorganisms. Cytometry 14: 136-143.

Ward BB, AH Devol, JJ Rich, BX Chang, SE Bulow, H Naik, A Pratihary \& A Jayakumar. 2009. Denitrification as the dominant nitrogen loss process in the Arabian Sea. Nature 461: 78-81.

Wentworth CK. 1922. A scale of grade and class terms for clastic sediments. Journal of Geology 30(5): 377-392.

Zarda B, D Hahn, A Chatzinotas, W Schönhuber, A Neef, R Amann \& J Zeyer. 1997. Analysis of bacterial community structure in bulk soil by in situ hybridization. Archives of Microbiology 168: 185-192.

Recibido el 20 de agosto de 2013 y aceptado el 21 de abril de 2014

Editor: Claudia Bustos D. 